\title{
Introducing a Levy Scheme to Online Educational Use of Copyrighted Works
}

\section{Weijie Huang*}

Law School, Shenzhen University, Shenzhen, Guangdong, 518073, China

\section{ARTICLE INFO}

Article history

Received: 6 August 2021

Revised: 14 August 2021

Accepted: 15 October 2021

Published Online: 30 October 2021

\section{Keywords:}

Copyright

Fair use

Compulsory licenses

Levy schemes

Online teaching

\section{Introduction}

To encourage creation and promote cultural development, copyright law awards authors an exclusive right to use their works within a certain period of time, meaning that anyone who wishes to use a work must obtain the authorization of the copyright owner. However, in some cases it is difficult for users to reach an agreement with the copyright owner. For example, the user wants to parody and satirize the copyrighted work and the copyright owner is worried that it will affect his own reputation, or the user is for non-profit purposes and thus is unwilling to spend time and money negotiating with the copyright owners. In order to save the transaction costs and to promote the circulation of knowledge, copyright law has crafted limitations and exceptions of

\section{ABSTRACT}

It is common for teachers to use others' copyrighted works for the purpose of teaching. The current copyright law in many nations only exempts educational use in the context of offline classroom teaching. The use of others' copyrighted material in online teaching may still constitute copyright infringement. To protect teachers from the chilling effect of copyright infringement, to safeguard the public's freedom to obtain knowledge, and to ensure the commensurability of the profits and responsibilities of online teaching platforms, this paper proposes a levy scheme for online teaching. Under the levy scheme, teachers are free to use others' published work for the purpose of online teaching, provided that such use does not conflict with a normal exploitation of the work and does not unreasonably prejudice the legitimate interest of the copyright owner. Online teaching platforms should remunerate the copyright owner of the work used in the platform according to the number of participants of the course that uses such work.

right. The most typical one is the doctrine of fair use, under which users may use a work for certain purposes without permission from and without remuneration to the copyright owner, provided that such use does not conflict with a normal exploitation of the work and does not unreasonably prejudice the legitimate interest of the copyright owner ${ }^{[1]}$. Since education can promote social and cultural development, many national copyright laws provide fair use protection for educational use ${ }^{[2]}$.

Nevertheless, the fair use doctrine for educational use has been designed for offline classing teaching. Whether the use of copyrighted material for online teaching is legal is unclear. Such uncertainty has caused chilling effects for teachers and schools, which in turn affects the effectiveness of online education which has become more and more important during the COVID-19 pandemic.

*Corresponding Author:

Weijie Huang,

Law School, Shenzhen University, Shenzhen, Guangdong, 518073, China;

Email: gdsthwj106@163.com 
Many uses that constitute fair use in offline classroom teaching, such as distributing sample essays to students for teaching and playing videos in courseware for illustration, would be considered illegal just because the course is conducted online. By examining the purpose of the fair use doctrine, Section 2 explains why educational use in the online environment should not be considered fair use. Since fair use is one of the limitations of copyright, Section 3 analyzes the applicability of other two limitations, i.e., compulsory licenses and levies, to online educational use. The paper concludes with a proposal for a levy scheme for the use of others' copyrighted material for online teaching.

\section{Educational Use under the Fair Use Doctrine}

The purpose of constructing fair use as well as other limitations of copyright is to prevent the exclusivity of copyright from prejudicing the public interests. The exclusivity of copyright has been regarded as a "necessary evil" ${ }^{[3]}$. The exclusivity of property right is determined by the physical characteristic of tangible property, that is, tangible property can only be possessed by one person, and only the possessor has the ability to dispose of it. On the contrary, the exclusivity of copyright is an "artificial" monopoly as the subject matter of copyright (i.e., a work) can be possessed by different people at the same time ${ }^{[4]}$. Copyright law confers on the author an exclusive right to exploit his/her work in order to prevent free-riding of copyrighted works and to provide economic incentives for creation, but at the expense of public access to knowledge. When the cost of the exclusive regime outweighs its benefits, the exclusive right should be limited. Education promotes social welfare so the use of copyrighted works for teaching purpose is normally regarded as fair use in national copyright laws.

In addition to bringing social benefits, another constitutive element of fair use is that it cannot unreasonably harm the interests of copyright owners. Therefore,

copyright laws of various countries generally require educational use to be non-commercial, and some additionally require the use should be conducted in non-commercial educational institution ${ }^{[5]}$. Limiting the teaching location to offline classrooms is also to avoid unreasonably harming the interests of copyright owners. Offline classrooms have physical boundaries with a limited number of students, which means that the dissemination of works is limited to a specific space and to a specific audience, so it will not affect the potential market for or value of the work.

However, it is difficult to limit the scope of the dissemination of works in the scenario of online teaching. Even if the teacher sets the account number and password of the classroom, students can easily share such information with others who have not enrolled in the course, especially in the case of anonymity. Moreover, with the widely available functions such as screenshots and recordings provided by online teaching platform, students are able to obtain courseware that embodies copyrighted works at basically zero cost, and share the courseware on the Internet. In other words, when the use of the copyrighted work occurs in the online environment, the copyright owner can hardly control the dissemination of the work. As educational use for online teaching probably harms the existing and future market for the work, such use can hardly be considered as fair use.

\section{The Applicability of Compulsory Licenses and Levy Schemes}

In addition to fair use, copyright law has also set up other limitations and exceptions, such as compulsory licenses and levies. This section intends to examine the applicability of these two limitations to online educational use. The doctrine of compulsory license allows the use of a copyrighted work without the permission of the copyright owner but requires the user to remunerate the copyright owner. Therefore, it is also named the "permitted-butpaid" rule ${ }^{[6]}$. The compulsory license has been provided for online educational use in some countries, but in a limited way. For example, China applies the "permittedbut-paid" rule to the use of certain types of copyrighted material to make courseware for implementing the nineyear compulsory educational program or the national educational plan online ${ }^{[7]}$. Nevertheless, the compulsory license is limited to use for the implementation of the "nine-year compulsory education or national education plan", which means that many non-profit public lectures and courses conducted online during the Covid-19 would still face the risk of copyright infringement.

A more serious problem is that online educational use is more compatible with levy schemes rather than compulsory licenses. A levy scheme, similar to a compulsory license, is also a "permitted-but-paid" rule. Under levy schemes, a use without the authorization 
from the copyright owner is permitted provided that the copyright owner has obtained remuneration from the such use. Nevertheless, levy schemes and compulsory licenses have different legislative purposes, as well as different way of implementation. Compulsory licenses have been designed to balance the protection of copyright and the prevention of copyright monopoly. A compulsory license is usually applied to situations where the copyright owner refuses to authorize a user due to the opportunism while such use is very important to the user ${ }^{[8]}$. Therefore, it is the actual users, usually professional users that use works on a large scale, who pay the royalties of compulsory licenses.

Levy schemes refer to rules that require the provider of the equipment or service that facilitates and profits from the use of copyrighted works to pay levies to copyright owners, and end users are exempted from their noncommercial, private use of copyrighted works. Levy schemes have usually been applied where a large number of end users make non-profit, private use of copyrighted works with the help of certain equipment or service ${ }^{[9]}$. Enforcing copyright against a critical mass of end users is difficult, but providing remuneration and incentives for copyright owners is crucial. By targeting intermediaries who profit from the use rather than non-commercial end users, levy schemes strike a balance between maintaining the incentives for creation and protecting the freedom and privacy of private use.

\section{Imposing a Levy to Online Educational Use}

The practice of online education and the number of its participants has been on the rise. Most of the participants of online education use courseware which embodies copyrighted works for personal study and research rather than for commercial purpose. While online teaching platforms have made profits from the use of copyrighted works through charging fees for courses, for certification, for software and for advertisement ${ }^{[10]}$. To strike a balance between protecting copyright and preserving the public's access to and use of knowledge, and to ensure the platforms' liability commensurate to their profits, it is necessary to impose a levy to online educational use. That is, it is free to use others' copyrighted works to prepare courseware for the purpose of online teaching without the authorization of the copyright owners, provided that such use does not conflict with the normal exploitation of the copyrighted works and the online teaching platform providing the course makes fair remuneration to the copyright owners.

The premise of applying the limitations of copyright to a user is that the user would not unreasonably harm the interests of the copyright owner. Although other existing levy schemes are applied to noncommercial use, because of the diverse management models on online teaching platforms and the ambiguous boundary between profit and non-profit, ${ }^{[1]}$ the levy scheme proposed here is restricted to the use that does not conflict with the normal exploitation of the work. Whether a use conflicts with the normal use of the work can be measured by the total revenue brought by the courses using the work to the online teaching platform. Based on empirical research, the Copyright Bureau and the Ministry of Education can set the upper limits on the revenue of courses in different fields. Once the revenue exceeds this upper limit, the levy scheme should not be applied and the use should subject to the exclusive right. By determining the threshold of the levy scheme for online educational use, the public's access to knowledge could be promoted and the incentives of copyright owners can be maintained.

\section{Funding}

This work was supported by Guangdong Planning Office of Philosophy and Social Sciences 2020 (project no. GD20YFX05).

\section{References}

[1] Article 9(2) of Berne Convention.

[2] Aufderheide P \& Jaszi P, 2011. Reclaiming Fair Use: How to Put Balance Back in Copyright. Chicago: University of Chicago Press, 12.

[3] Boyle J, 2003. The second enclosure movement and the construction of the public domain, Law and Contemporary Problems, 66(1/2): 54.

[4] Vaidhyanathan S, 2003. Copyrights and Copywrongs: The Rise of Intellectual Property and how it Threatens Creativity. New York: New York University Press, 20.

[5] Although China's Copyright Law and the Implementation Regulations of the Copyright Law do not clarify whether the educational use should be restricted in non-profit educational institutions, the Guidelines for the Trial of Copyright Infringement Cases issued by the Intellectual Property Rights Tribunal of Higher People's Court of Beijing clarify that fair use should 
not be applied to for-profit educational institution.

[6] Ginsburg J C, 2015. Fair use for free, or permitted-but-Paid?, Berkeley Technology Law Journal, 29(3): 1384.

[7] Article 8 of the Regulations for the Protection of the Right of Communication through Information Network of China.

[8] Abrams H B, 2009. Copyright's first compulsory license, Santa Clara Computer \& High Technology Law Journal, 26(2): 215.
[9] Netanel N W, 2003. Impose a noncommercial use levy to allow free peer-to-peer file sharing, Harvard Journal of Law \& Technology, 17(1): 5.

[10] Jia Y et al., 2017. Towards economic models for MOOC pricing strategy design. In: Proceedings of International Conference on Database Systems for Advanced Applications. Berlin: Springer, 387-388.

[11] Dahdouh K et al., 2018. Big data for online learning systems. Education and Information Technologies, 23(6): 2786. 